\title{
Regulators confront blind spots in research oversight
}

Investigators of scientific misconduct have had their hands full in recent months. So far this year, a regional hospital in western Massachusetts has announced the discovery of what may be the biggest case of research fraud in history, scientists in Texas have used a new computer algorithm to uncover thousands of apparently plagiarized papers in peer-reviewed journals and a congressional subcommittee questioned the consistency of institutional and independent review boards (IRBs) that oversee clinical trials (see 'Coast IRB hits treacherous waters' on page 470 of this issue).

The case of Scott Reuben, a researcher at Baystate Hospital in Springfield, Massachusetts, surfaced through the sort of routine review most researchers consider a formality. "What we did last year was to ask our IRB to look at [...] almost 100 abstracts that were submitted to identify that each of the studies had the appropriate IRB oversight," says Hal Jenson, the hospital's chief academic officer. According to Jenson, "it was during this process that we identified two studies that did not have IRB approval."

Reuben was a coauthor on both of the unapproved studies, but the hospital says that was only the tip of the iceberg. At least 21 published papers have now been found to contain allegedly fake data from Reuben. Investigators say that, in at least some instances, his clinical results seem to have come from patients who were entirely fictitious. The scope of the apparent fraud is breathtaking, potentially undermining an entire subdiscipline of pain control called multimodal anesthesia, which combines various pain drugs.

As soon as the review committee began investigating, Reuben took leave. Paul Cirel,

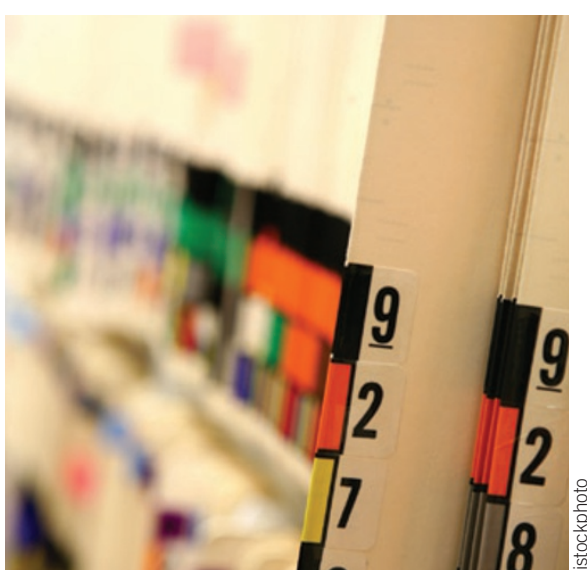

Case control: Trials allegdly faked patients
Reuben's attorney with the Boston firm of Dwyer and Collora, issued only a brief statement on the matter, concluding that "Dr. Reuben deeply regrets that all of this happened. With the committee's guidance, he is taking steps to ensure that this never happens again."

Although Reuben has been banned from working at Baystate for ten years and may face further legal action, it might be impossible to guard against similar cases in the future. "I don't have an answer of how to identify [...] somebody who fraudulently betrays us," says Jenson, adding that "science as a whole, and the peer review system especially, is built around trust, and if that trust is betrayed, it undermines the entire system."

Other types of misconduct could be relatively easy to detect, particularly as journal archives move online. That became clear when researchers searched the biomedical literature online with a new computer algorithm. The study revealed that many scientists take the idea of reproducible results a bit too literally (Science 323, 1293-1294; 2009).

"Originally, the algorithm was developed as kind of a natural language text-searching alternative," says Mounir Errami, an instructor in internal medicine at the University of Texas Southwestern Medical Center in Dallas, Texas and an author on the new study. Rather than hunting for keywords, as most current search methods do, the algorithm looks at full sentences and other linguistic parameters. "There are some [additional steps] to try to improve over the similarity search," says Errami.

Applying the program to a database of eight million peer-reviewed papers, Errami and his colleagues found tens of thousands of apparent duplications. "We never make a judgment call whether there is some plagiarism or not. What the tool tells you is [whether] there is [...] a very high similarity between two pieces of text written by different authors, and that's something that may need to be looked at," explains Errami.

From the initial hits, the investigators have manually confirmed about 200 cases of apparent copying, a number that is likely to grow. "Overall there are about 10,000 papers that are waiting for us to inspect them visually," says Errami.

When they have confirmed duplication, the researchers notify the authors of both papers and the journals that published them, often prompting retractions. "What we were surprised with was how it was possible for

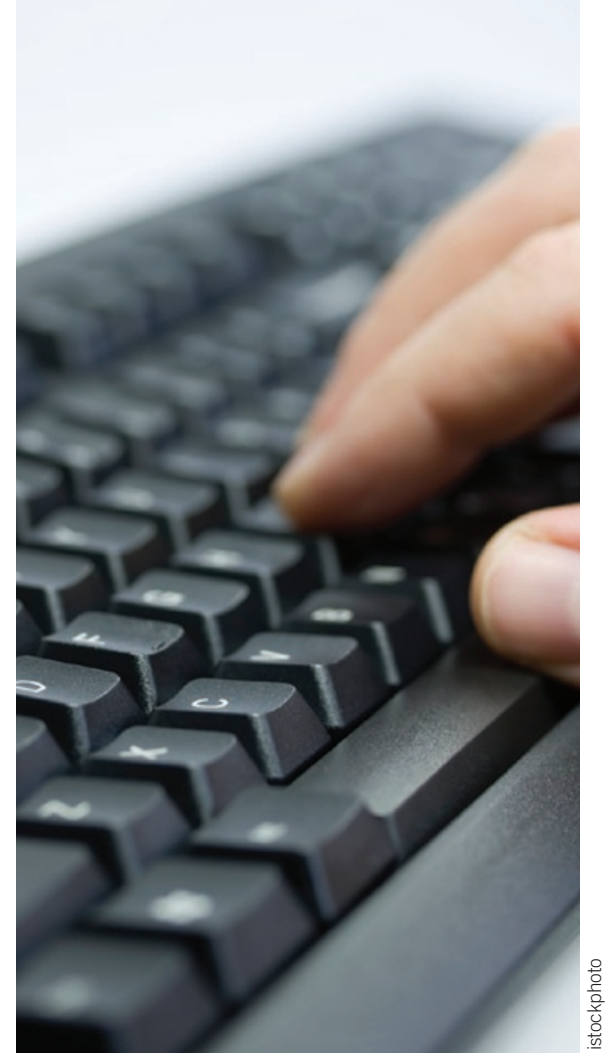

Double trouble: An algorithm finds duplication

certain people to copy $60-70 \%$ of a paper word for word, comma for comma, and yet get that paper published in a peer-reviewed journal," says Errami, adding that "it highlighted the lack of tools to identify these cases." With the ongoing project drawing new attention to plagiarism, though, Errami hopes journals will become more vigilant.

Alan Dove, Springfield, Massachusetts

\section{Correction:}

In the April issue of Nature Medicine the feature on clioquinol ('The curious case of clioquinol', Nat. Med. 15, 356-359; 2009) cited Ashley Bush of the Mental Health Research Institute in Melbourne, Australia, as the sole originator of the metals theory for Alzheimer's disease, and Prana Biotechnology as being founded in Melbourne. The theory and Prana Biotechnology were jointly developed by Bush and Rudolph Tanzi of Massachusetts General Hospital, with the help of Rob Moir, and in collaboration with Colin Masters of the University of Melbourne. Additionally, it was Michel Xilinas who recognized the chelating properties of clioquinol. 